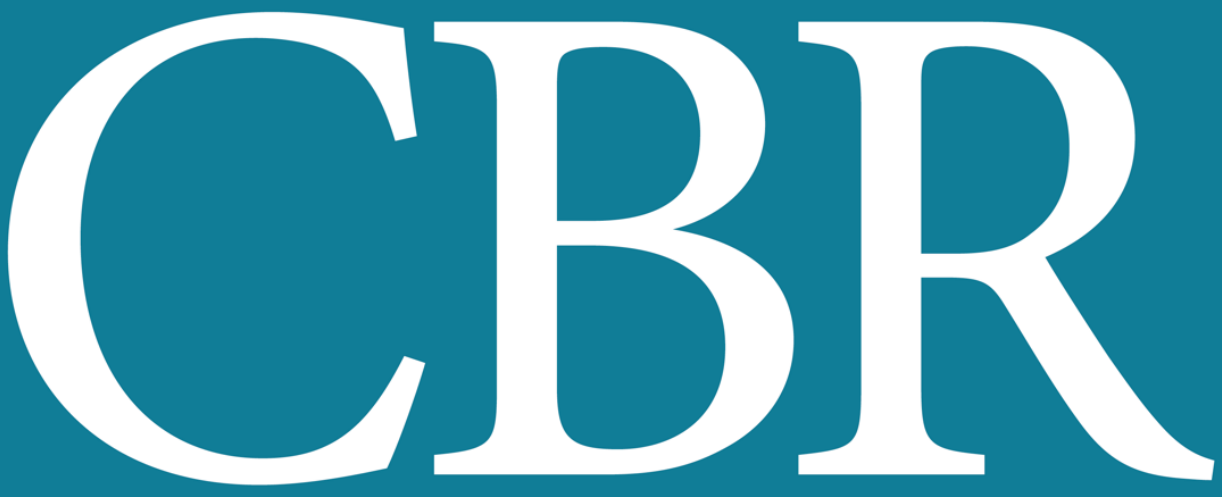

INTERNATIONAL JOURNAL OF CANCER AND BIOMEDICAL RESEARCH

https://jcbr.journals.ekb.eg

Editor-in-chief

Prof. Mohamed Labib Salem, PhD

Comparative study of BAP1 and CD147 expression in diagnosis of malignant mesothelioma

Nehal A.Heabah and Asmaa M.Eid 


\section{Welcome letter from Editor-in-Chief}

Welcome to the Int J Cancer and Biomedical Research (IJCBR)!

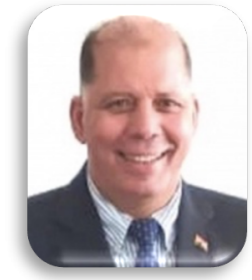

It is with great pleasure that I write this editorial to welcome you to the IJCBR. This journal provides a platform for publication of original and reviews research articles, short communications, letter to editor, thesis abstract, conference report, and case studies. These types of publication are directed at the interface of the fields of cancer and biomedical research.

The IJCBR relies on a distinguished expert of the Advisory and Editorial Board Members from the top international league covering in depth the related topics. They timely review all manuscripts and maintain highest standards of quality and scientific methodology and ethical concepts. Meanwhile, we take all possible means to keep the time of the publication process as short as possible.

I take this chance to welcome your contributions to the IJCBR and have every expectation that it will soon become one of the most respected journals in both the fields of cancer and biomedical research.

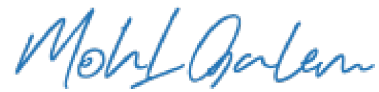

Mohamed L. Salem,

Editor in Chief 


\title{
Comparative study of BAP1 and CD147 expression in the diagnosis of malignant mesothelioma
}

\author{
Nehal Abd El-Ghaffar Heabah and Asmaa Mustafa Eid \\ Pathology Department, Faculty of Medicine, Tanta University, Tanta, Egypt
}

\section{III \\ ABSTRACT}

10 ARTICLE INFO

Background: Malignant mesothelioma (MM) is a lethal tumor of serosal surfaces. Its differentiation from reactive mesothelial hyperplasia is mandatory, and may be problematic in many situations. Thus, the application of a targeted panel of specific markers permits proper diagnosis in the majority of cases. Aim: This study aimed to determine the potential use of BRCA associated protein-1 (BAP1) and CD147 antibodies to differentiate between $\mathrm{MM}$ and reactive mesothelial hyperplasia. Materials and Methods: The current work was carried out on 120 cases (56 reactive mesothelial hyperplasia and 64 malignant mesothelioma cases), retrieved as 70 cell blocks and 50 tissue samples. Immunohistochemical staining, using calretinin (to confirm the mesothelial lineage), BAP1, and CD147 antibodies, was performed for each case. Results: Lost nuclear BAP1 expression was detected in $45.3 \%$ of the mesotheliomas versus $19.6 \%$ of reactive mesothelial hyperplasia cases. Positive membranous CD147 expression was found in $84.4 \%$ of mesothelioma cases versus $8.9 \%$ of reactive mesothelial hyperplasia cases. BAP1 showed $44.6 \%$ sensitivity and $80 \%$ specificity, while CD147 showed $84.3 \%$ sensitivity and $91 \%$ specificity in the diagnosis of malignant mesothelioma. Conclusions: The loss of BAP1 expression and positive CD147 expression could be of diagnostic value for malignant mesothelioma and can exclude the diagnosis of reactive mesothelial proliferations in both biopsy and cytology specimens. CD147 exhibits higher sensitivity and specificity than BAP1.

Keywords: Malignant mesothelioma; reactive mesothelial hyperplasia; BAP1; CD147

Editor-in-Chief: Prof. M.L. Salem, PhD - Article DOI: 10.21608/jcbr.2020.36829.1059

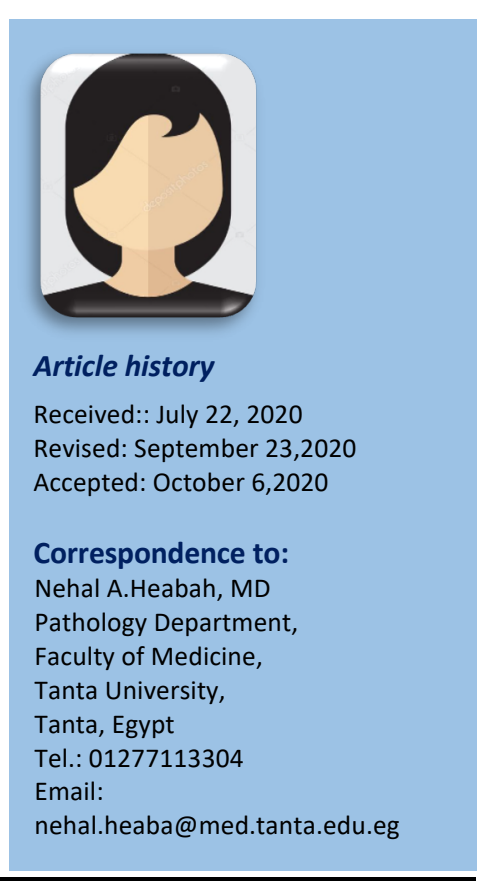

\section{INTRODUCTION}

Malignant mesothelioma ( $\mathrm{MM}$ ) is an aggressive tumor of mesothelial origin, involving mainly the pleura; with an increasing incidence worldwide, due to asbestos exposure. MM is related to poor survival, particularly for the pleomorphic and sarcomatoid/desmoplastic variants (Robinson and Lake, 2005).

Early appropriate diagnosis of MM may improve patient outcomes. However, it may be difficult to differentiate between a wide spectrum of reactive and neoplastic mesothelial proliferations, depending only on routine histologic examination. MM cells may appear innocent, while hyperplastic mesothelial cells may exhibit various degrees of cellular atypia; especially, in cytological specimens. Also, it's difficult to identify the invasive component of MM in small biopsies. Superficial entrapment of mesothelial cells by organized effusion is common in reactive mesothelial proliferations, which may be confused with malignant invasion (Minato et al., 2014). Thus, many studies investigated the role of novel biomarkers in an attempt to differentiate between $\mathrm{MM}$ and reactive mesothelial cells. However, the results of those studies were contradictory (Chapel et al., 2020).

BRCA associated protein-1 (BAP1) is a tumor suppressor gene, located at $3 \mathrm{p} 21$. BAP1 acts as a deubiquitinating enzyme, involved in the removal of ubiquitin from proteins (McGregor et al., 2015 and Boffetta et al., 2018). Nuclearlocalized, ubiquitin carboxy-terminal hydrolase proteins play an important role in the ubiquitindependent proteasome pathway, which is responsible for protein degradation. This process is necessary for removal of abnormally folded or damaged proteins, regulation of gene 
transcription, and DNA damage repair responses. Disruption of ubiquitin-dependent proteasome pathway is related to several cancer types and could be a potential target for anti-cancer therapies (Cigognetti et al., 2015).

BAP1 also modulates calcium-induced apoptosis, and so, its mutation ends in accumulation of DNA-damaged cells with a high susceptibility to develop malignancy, as seen in malignant mesothelioma, uveal tract and cutaneous melanoma (Carbone et al., 2012; Baumann et al., 2015 and Bononi et al, 2017). Mutation of BAP1, identified as undetectable nuclear immunoreactivity, has been suggested as a potential marker to identify $M M$, particularly in small biopsies (Erber et al., 2020). CD147 (or Extracellular matrix metalloproteinase inducer "EMMPRIN"), is a cell surface glycoprotein and a member of immunoglobulin superfamily (Ig SF) [that are involved in the recognition, binding, or adhesion processes of cells]. CD147 plays a role in intercellular communication, involved in many immune-related functions, differentiation, and development (Dai et al., 2013). It's the chaperone of monocarboxylate transporters (MCTs), which mediate the transmembrane co-transport of lactate, thereby, regulating $\mathrm{pH}$ of the tumor microenvironment.

CD147 also acts as a key marker of cell invasion and metastasis in many cancers, via production of numerous matrix metalloproteinases. Its expression is related to advanced stage, higher grade, lymphovascular invasion, and decreased overall survival. CD147 dampens host immune defenses and favors chemoresistance (Afonso et al., 2009). So, CD147 silencing could be a target for therapeutic strategies in many tumors, including MM (Pinheiro et al., 2012).

In the current study, we aimed to investigate the potential diagnostic role of BAP1 and CD147 in differentiating $\mathrm{MM}$ and reactive mesothelial hyperplasia.

\section{MATERIALS AND METHODS}

This retrospective study was carried out on 120 formalin-fixed paraffin-embedded (FFPE) blocks (56 reactive mesothelial hyperplasia and 64 malignant mesothelioma cases). Cases were retrieved as 70 cell blocks of cytological preparations and 50 tissue biopsy samples.

These cases were selected from the archives of the Pathology Department, Faculty of Medicine, Tanta University, during the period of the study from March 2019 to June 2020, depending on quality of the blocks and presence of full clinical data. Approval from the research ethics committee, Faculty of Medicine, Tanta University, was obtained before conducting the study.

All cases were stained by routine H\&E staining, for proper re-evaluation and by calretinin immunohistochemical staining (clone $\mathrm{H}-5$ : sc365956, Santa Cruz Biotechnology, INC, USA, dilution 1:100), to confirm the mesothelial origin of the selected cases. Sections of the obtained blocks ( $5 \mu \mathrm{m}$ thick), on positively charged slides, were left to dry for 30 minutes at $37^{\circ} \mathrm{C}$. Deparaffinization and antigen retrieval were performed in a Dako PT Link unit. Both high and low pH EnVisionTM FLEX Target Retrieval Solutions were used at $97^{\circ} \mathrm{C}$ for 20 min. Dako automated immune-stainer (Link 48) was used for immunostaining.

Anti-BAP1 antibody, a mouse monoclonal antibody (clone C-4, sc-28383, Santa Cruz Biotechnology, INC, USA) and anti-CD147 antibody, a mouse monoclonal antibody (clone 8D6: sc-21746, Santa Cruz Biotechnology, INC, USA) were used as primary antibodies. The slides were incubated with the primary antibodies for 30 minutes, following treatment with a peroxidase-blocking reagent for 5 minutes; with subsequent addition of horseradish peroxidase (HRP) reagent for 20 min and diaminobenzidine (DAB) chromogen solution for 10 minutes. Hematoxylin was applied for counterstaining.

\section{Assessment of BAP1 immunohistochemical results}

Only nuclear immunoreactivity, at any percentage, was considered positive (although some cases showed finely granular cytoplasmic reaction; interpreted as negative reaction according to Chapel et al., 2020). Positive internal control for BAP1 was observed in normal/reactive mesothelial cells and stromal fibroblastic cells, as nuclear brownish staining 
(inflammatory cells and vascular endothelium may show non-specific staining, as well).

\section{Assessment of CD147 immunohistochemical results}

Considering both the intensity and extent of CD147 expression; the final score (ranging from 0-6) was determined. The intensity of staining was scored as follows: 0: negative; 1 : weak; 2 : intermediate; and 3: strong. CD147 staining extent was scored as follows: 0 : $0 \%$ of immunoreactive cells; 1 : $<5 \%$ of immunoreactive cells; 2: $5-50 \%$ of immunoreactive cells; and 3 : $>50 \%$ of immunoreactive cells. Final scores $\geq 3$ were considered positive (Pinheiro et al., 2012). Sections of urothelial carcinoma were used as a positive control for CD147, in which CD147 expressed as brownish membranous staining in the tumor cells.

\section{Statistical analysis}

The collected data were statistically analyzed using the SPSS software statistical computer package (version 23, Armonk, NY: IBM Corp). Data were expressed in terms of frequencies and percentages for categorical variables; range, median, and mean \pm standard deviation (SD) for continuous variables.

To confirm the diagnostic role of BAP1 and CD147; the sensitivity, specificity, positive predictive value (PPV), negative predictive value (NPV), and accuracy for each marker were calculated as follows:

Sensitivity:True positive/(True positive + False negative) $\times 100$

Specificity:True negative/(True negative + False positive) $\times 100$

PPV:True positive / (True positive + False positive) $\times 100$

NPV:True negative / (True negative + False negative) $\times 100$

Accuracy:(True positive + True negative) / (True positive + True negative + False positive + False negative) $\times 100$

Statistical relation between BAP1 and CD147 was performed using McNemar test. P-value of $<0.05$ was considered statistically significant.

\section{RESULTS}

\section{Clinicopathological data}

This study included 120 mesothelial specimens; whose ages ranged from 40 to 75 years (median 57.5 years). Regarding the sex of the studied cases, 101 cases (84.2\%) were males and 19 cases $(15.8 \%)$ were females. One hundred cases (83.3\%) were pleural in origin and the remaining 20 cases $(16.7 \%)$ were peritoneal. Out of the studied cases, 64 cases (53.3\%) were malignant mesotheliomas (including 56 cases epithelioid and 8 cases Sarcomatoid mesothelioma) and 56 cases $(46.7 \%)$ were reactive mesothelial hyperplasia. Clinicopathological characteristics of studied cases are summarized in Table 1.

\section{Immunohistochemical staining results of BAP1}

Lost nuclear BAP1 expression was detected in $33.3 \%$ of all the studied cases. Among the cases of mesothelioma; $45.3 \%$ showed negative BAP1 expression: $46.4 \%$ of the epithelioid mesothelioma cases and $37.5 \%$ of the sarcomatoid mesotheliomas showed lost nuclear BAP1 staining. Regarding reactive mesothelial hyperplasia cases; $19.6 \%$ showed lost nuclear BAP1 expression (Table 2 and Figure 1).

\section{Immunohistochemical staining results of CD147}

Positive CD147 expression was demonstrated as membranous staining in $49.2 \%$ of our cases. Among mesothelioma cases; $84.4 \%$ showed positive CD147 expression $185.7 \%$ of the epithelioid mesothelioma cases and $75 \%$ of the sarcomatoid mesotheliomas were CD147 positive). As regard to reactive mesothelial hyperplasia cases; only $8.9 \%$ showed CD147 positivity (Table 3 and Figure 2). The sensitivity, specificity, PPV, NPV, and accuracy of BAP1 and CD147 in the diagnosis of malignant mesothelioma are summarized in Table 4. CD147 showed higher sensitivity, specificity, PPV, NPV, and accuracy than BAP1.

Table 5 shows a statistically significant negative relation between BAP1 expression and CD147 immunoreactivity in the studied mesothelial cases $(P=0.026)$. As $75 \%$ of cases with lost BAP1 expression, showed positive CD147 staining; while $63.7 \%$ of cases with retained BAP1 expression, showed CD147 negative staining. 
Table 1. The clinicopathological characteristics of the studied cases

\begin{tabular}{lcc}
\hline Clinicopathological characteristics & Cases (No.) & $\%$ \\
\hline Age in years \pm SD (range) & $57.5 \pm 8.605$ (40-75) & \\
Sex & & \\
Male & 101 & $84.2 \%$ \\
Female & 19 & $15.8 \%$ \\
Specimen & & \\
Cell blocks (Cytology) & 70 & $58.3 \%$ \\
Tissue biopsy & 50 & $41.7 \%$ \\
Location & & \\
Pleural & 100 & $83.3 \%$ \\
Peritoneal & 20 & $16.7 \%$ \\
Histopathological types & & \\
Mesothelioma (total) & & \\
$\quad$ Epithelioid & 64 & $53.3 \%$ \\
$\quad$ Sarcomatoid & 56 & $46.7 \%$ \\
Reactive mesothelial hyperplasia & 8 & $6.6 \%$ \\
& 56 & $46.7 \%$ \\
\hline
\end{tabular}

Table 2. BRCA associated protein-1 (BAP1) expression in the studied cases

\begin{tabular}{lccc}
\hline BAP1 expression & Cases (No.) & Lost expression N (\%) & Retained expression N (\%) \\
\hline Total & 120 & $40(33.3)$ & $80(66.7)$ \\
Histopathological types & & & \\
Mesothelioma & 64 & $29(45.3)$ & $35(54.7)$ \\
$\quad$ Epithelioid & 56 & $26(46.4)$ & $30(53.6)$ \\
$\quad$ Sarcomatoid & 8 & $3(37.5)$ & $5(62.5)$ \\
Reactive mesothelial hyperplasia & 56 & $11(19.6)$ & $45(80.4)$ \\
\hline
\end{tabular}

Table 3. CD147 expression in the studied cases

\begin{tabular}{lccc}
\hline CD147 expression & Cases (No.) & Positive expression N (\%) & Negative expression N (\%) \\
\hline Total & 120 & $59(49.2)$ & $61(50.8)$ \\
Histopathological types & & & \\
Mesothelioma & 64 & $54(84.4)$ & $10(15.6)$ \\
$\quad$ Epithelioid & 56 & $48(85.7)$ & $8(14.3)$ \\
$\quad$ Sarcomatoid & 8 & $6(75)$ & $2(25)$ \\
Reactive mesothelial hyperplasia & 56 & $5(8.9)$ & $51(91.1)$ \\
\hline
\end{tabular}

Table 4. The sensitivity, specificity, PPV, NPV, and accuracy of BRCA associated protein-1 (BAP1) and CD147 in the diagnosis of malignant mesothelioma

\begin{tabular}{cccccc}
\hline & Sensitivity (\%) & Specificity (\%) & PPV* (\%) & NPV** (\%) & Accuracy (\%) \\
\hline BAP1 & 44.6 & 80 & 72.5 & 56.3 & 61.7 \\
CD147 & 84.3 & 91 & 91.5 & 83.6 & 87.5 \\
\hline
\end{tabular}

*PPV, Positive predictive value, **NPV, Negative predictive value

Table 5. The relation between BRCA associated protein-1 (BAP1) and CD147 expression in the studied cases

\begin{tabular}{|c|c|c|}
\hline \multirow{2}{*}{ BAP1 $(n=120)$} & \multicolumn{2}{|c|}{ CD147 (n=120) } \\
\hline & Positive (n=59) N (\%) & Negative $(n=61) N(\%)$ \\
\hline Retained $(n=80)$ & $29(36.3)$ & $51(63.7)$ \\
\hline Lost $(n=40)$ & $30(75)$ & $10(25)$ \\
\hline$P$ & \multicolumn{2}{|c|}{$0.026^{*}$} \\
\hline
\end{tabular}



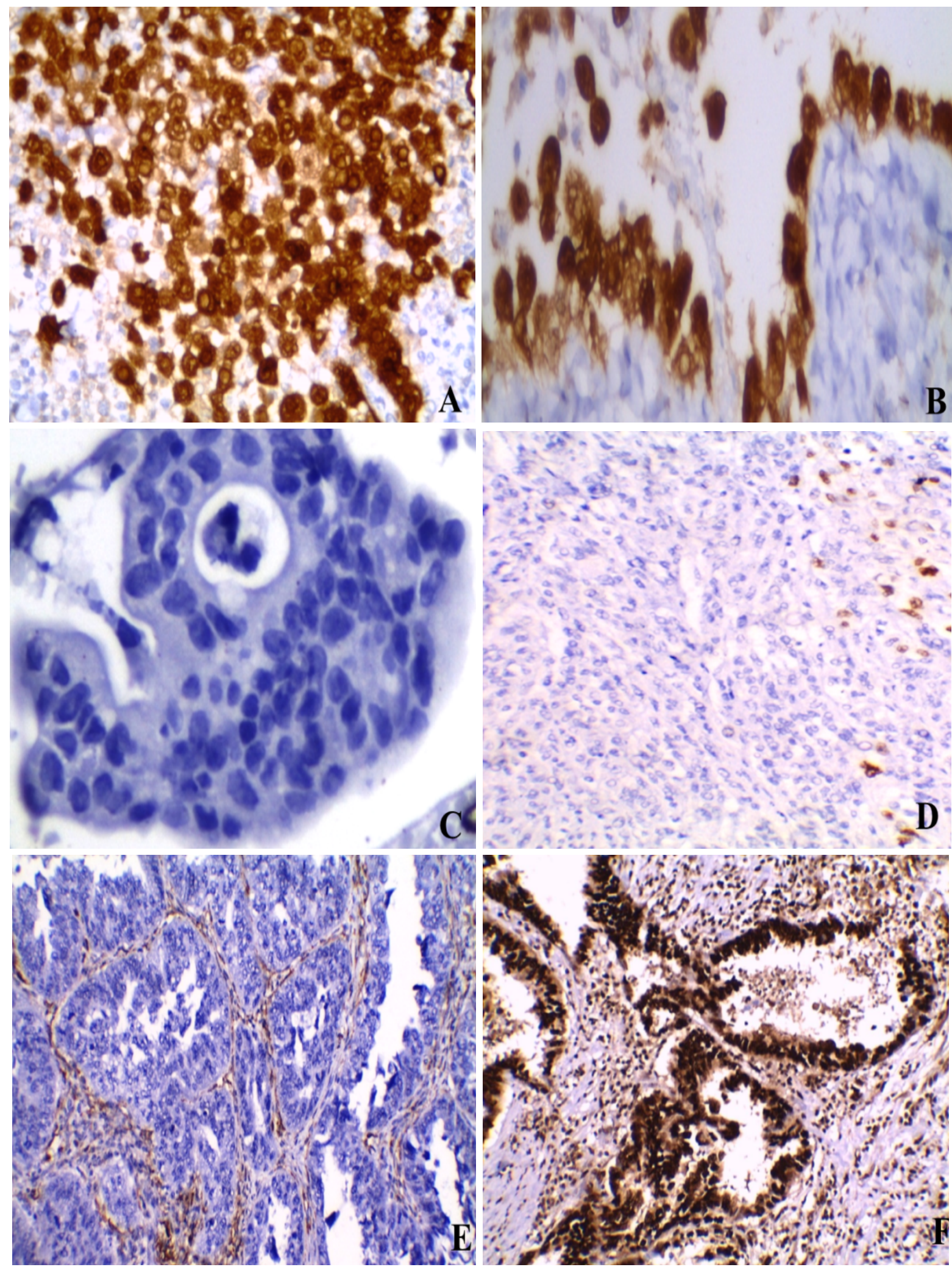

Figure 1. Reactive mesothelial hyperplasia showing retained nuclear BRCA associated protein-1 (BAP1) expression on cytological specimen (cell block) (x400) (A), and tissue biopsy specimen (x400) (B), Malignant mesothelioma cells showing negative nuclear BAP1 expression on cytological specimen (cell block) (x400) (C), and tissue biopsy specimen (x200) (D), Malignant mesothelioma (epithelioid type) showing negative BAP1 expression on tissue biopsy specimen, with surrounding BAP1 positive stromal cells $(\mathrm{X} 200)(\mathrm{E})$, Malignant mesothelioma (epithelioid type) showing positive BAP1 expression on tissue biopsy specimen, with surrounding BAP1 positive stromal and inflammatory cells (x200) (F). 


\section{DISCUSSION}

Malignant mesothelioma (MM) is a rare lethal tumor of the serosal surfaces. Its prognosis is poor, with a median survival time rarely exceeding 12 months (Robinson and Lake, 2005 and Ray and Kindler, 2009).

Accurate pathologic diagnosis of MM leads to early proper therapy, including surgery, and can improve the patients' outcomes. Distinction between malignant mesothelioma and benign mesothelial proliferations is challenging in many conditions; especially in tiny specimens, where stromal invasion cannot be assessed or cytological samples, where tumor architecture is difficult to evaluate (Monaco et al., 2018 and Chapel et al., 2020).

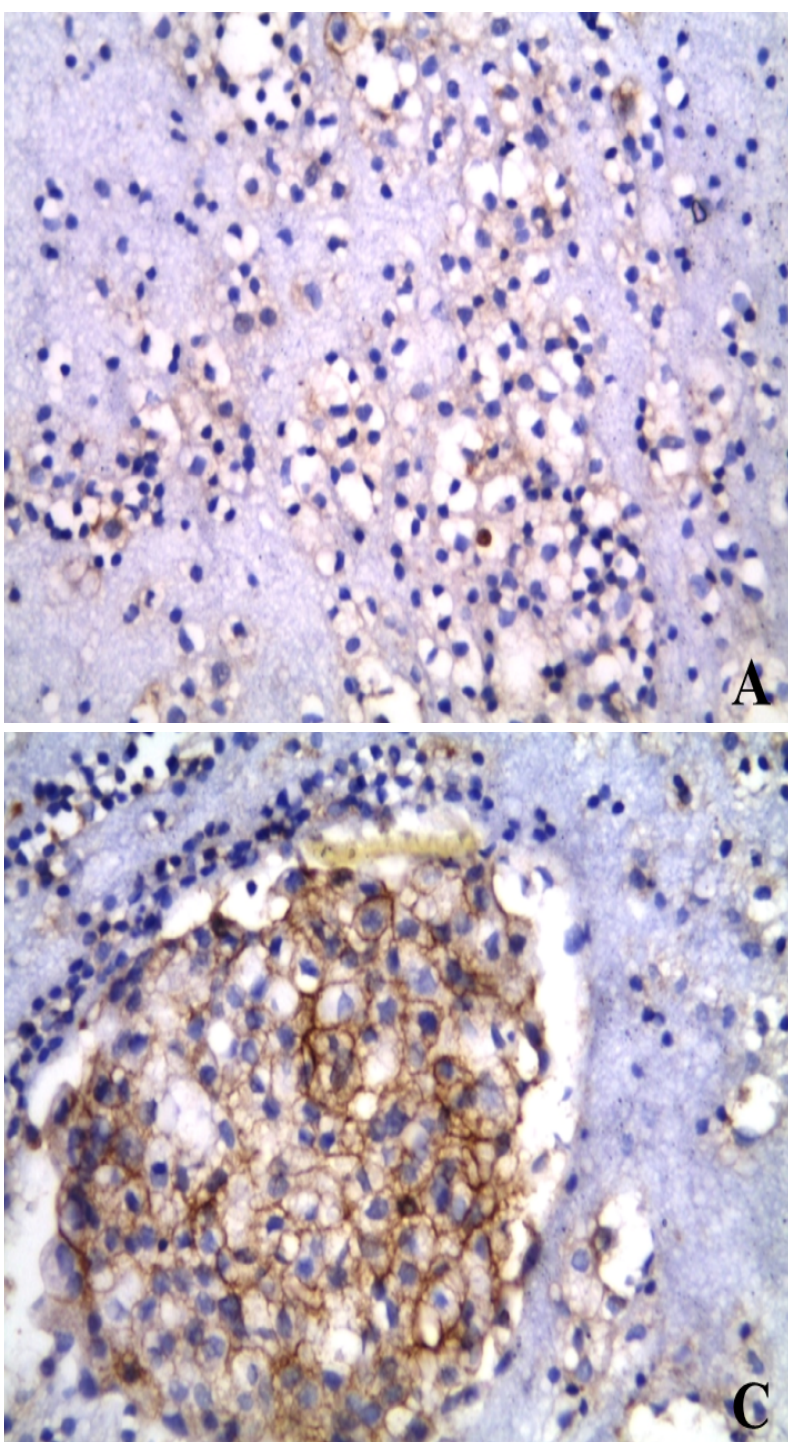

To differentiate, many immunohistochemical markers have been developed, but their significance remains controversial, with marked variation in their sensitivity and specificity among various reports.

In this study, we evaluated the diagnostic role of BAP1 and CD147 immunohistochemical expression in differentiating malignant mesothelioma and reactive mesothelial hyperplasia. Regarding BAP1 expression, $45.3 \%$ of the studied mesothelioma cases showed lost BAP1 expression, in contrast to cases of reactive mesothelial hyperplasia, which showed loss of BAP1 expression among only $19.6 \%$.

Figure 2. Reactive mesothelial hyperplasia showing negative CD147 expression on cytological preparation (cell block) (x400) (A), Malignant mesothelioma cells showing positive CD147 expression on cytological specimen (cell block) (x200) (B), Malignant mesothelioma cells showing positive CD147 expression, compared to negative CD147 expression of the surrounding reactive mesothelial cells on cytological specimen (cell block) (x400) (C), Malignant mesothelioma (epithelioid type) showing positive CD147 expression on tissue biopsy specimen (x400) (D). 
These results matched those of Erber et al., 2020, who observed lost BAP1 expression among $56.4 \%$ of their MM cases. Kinoshita et al., 2018 (a) also studied BAP1 to differentiate sarcomatoid mesothelioma and fibrosing pleuritis and found that BAP1 showed $100 \%$ specificity (using both IHC and FISH technology). According to other studies, BAP1 loss is also $100 \%$ specific for malignancy in mesothelial proliferations (Hida et al., 2017; Berg et al., 2018; Hatem et al., 2019, and Yoshimura et al., 2019). The lower BAP1 specificity in our study, compared with the previous studies, maybe due to lack of genomic analysis, or different ways to interpret BAP1 immunostaining.

According to our results, BAP1 was relatively insensitive marker (low sensitivity of $44.6 \%$ ) in detecting malignant mesothelioma. Our results matched those of Nasu et al., 2015; Hwang et al., 2016(a); Righi et al., 2016; Hida et al., 2017; Yoshimura et al., 2017; Chou et al., 2018; Kinoshita et al., 2018(b), and Yoshimura et al., 2019, who all reported low BAP1 sensitivity, ranging from $50-65 \%$.

The PPV of BAP1 in the diagnosis of MM in this study was $72.5 \%$; however according to both Cozzi et al., 2018 and Cigognetti et al., 2015, the PPV of BAP1 reached $100 \%$. The NPV value of BAP1 in the diagnosis of MM in the current study was $56.3 \%$. Slightly lower results were detected by Cozziet al., 2018, who reported 49.3\% NPV in their work. Cigognetti et al., 2015 stated that the NPV of BAP1 in their study was $90 \%$. Hwang et al., 2016b reported that BAP1 and p16 are not lost in all MM, using FISH analysis, and even when used together, lost expression couldn't confirm the malignant nature of the lesions. Husain et al., 2018 stated that loss of nuclear BAP1 expression is a malignancy indicator, but it does exclude a benign diagnosis. Accordingly, interpretation of BAP1 expression should be done with caution, especially when considering a primary diagnosis of malignant mesothelioma and it is better confirmed by another marker.

In our work, lost nuclear BAP1 expression was detected in $46.4 \%$ versus $37.5 \%$ of the epithelioid and sarcomatoid mesotheliomas, respectively. These results were agreed with
Erber et al., 2020, who stated that $55.4 \%$ of epithelioid and $41.7 \%$ of sarcomatoid MM were

BAP1-deficient. Bott et al., 2011, did not find a relation between BAP1 (by genomic analysis) and histologic mesothelioma variants. On the contrary, Cigognetti et al., 2015, found a striking difference in BAP1 loss among epithelioid and sarcomatoid mesothelioma (69\% versus $15 \%$ ). Shinozaki-Ushiku et al., 2017 reported BAP1 loss in $61 \%$ of epithelioid versus $0 \%$ loss among sarcomatoid variants of $\mathrm{MM}$. Owing to low sensitivity of BAP1 in the diagnosis of malignant mesothelioma, we studied CD147 expression among benign and malignant mesothelial proliferations, to determine if it has better diagnostic utility. Regarding CD147 expression in this study, $84.4 \%$ of the studied mesothelioma cases showed positive CD147 expression, versus $8.9 \%$ of reactive mesothelial hyperplasia cases. CD147 showed $84.3 \%$ sensitivity and $91 \%$ specificity in the diagnosis of malignant mesothelioma (both were higher than BAP1).

Only few studies have investigated CD147 expression among reactive mesothelial cells and mesothelioma cases. The main was of Pinheiro et al., 2012, who stated that CD147 can distinguish these two proliferations and that CD147 could be a target for MM targeted therapy. Their sample size was small (20 cases), and they found that CD147 was significantly expressed in $90 \%$ (8/9) of MM vs. 9\% (1/11) for mesothelial reactive cells, with $88.8 \%$ sensitivity and $90.9 \%$ specificity. Later on, Paintal et al., 2013, recommended further study of CD147 expression among mesothelial cases to determine its diagnostic validity and explore its potential therapeutic use.

\section{CONCLUSION}

Positive CD147 expression and lost BAP1 expression may be diagnostic of malignant mesothelioma and can exclude the diagnosis of reactive mesothelial proliferations. CD147 exhibits higher sensitivity, specificity, PPV, NPV and accuracy than BAP1. Further studies, using $\mathrm{IHC}$ and gene analysis, are required to confirm the validity of the current results in diagnosis of benign and malignant mesothelial proliferations, and to explore the potential therapeutic role of BAP1 and CD147 in MM. 


\section{CONFLICTS OF INTEREST}

All authors declared no conflict of interest.

\section{FUNDING}

No fund was received for this work.

\section{REFERENCES}

Afonso J, Santos LL and Amaro T (2009). The aggressiveness of urothelial carcinoma depends to a large extent on lymphovascular invasion - the prognostic contribution of related molecular markers. Histopathology, 55(5):514-524.

Andrici J, Sheen A and Sioson L (2015). Loss of expression of BAP1 is a useful adjunct, which strongly supports the diagnosis of mesothelioma in effusion cytology. Mod Pathol, 28(10):1360-1368.

Baumann F, Flores E and Napolitano A (2015). Mesothelioma patients with germline BAP1 mutations have 7-fold improved long-term survival. Carcinogenesis, 36(1):76-81.

Berg KB, Dacic S and Miller C (2018). Utility of Methylthioadenosine Phosphorylase Compared With BAP1 Immunohistochemistry, and CDKN2A and NF2 Fluorescence In Situ Hybridization in Separating Reactive Mesothelial Proliferations From Epithelioid Malignant Mesotheliomas. Arch Pathol Lab Med, 142(12):1549-1553.

Boffetta P, Righi L and Ciocan C (2018). Validation of the diagnosis of mesothelioma and BAP1 protein expression in a cohort of asbestos textile workers from Northern Italy. Ann Oncol, 29(2):484-489.

Bononi A, Giorgi C and Patergnani S (2017). BAP1 regulates IP3R3-mediated $\mathrm{Ca} 2+$ flux to mitochondria suppressing cell transformation. Nature, 546(7659):549-553.

Bott M, Brevet M and Taylor BS (2011). The nuclear deubiquitinase BAP1 is commonly inactivated by somatic mutations and 3p21.1 losses in malignant pleural mesothelioma. Nat Genet, 43(7):668-672.

Carbone M, Ferris LK and Baumann F (2012). BAP1 cancer syndrome: malignant mesothelioma, uveal and cutaneous melanoma, and MBAITs. $J$ Transl Med, 10(1):179.

Chapel DB, Schulte JJ and Husain AN (2020). Application of immunohistochemistry in diagnosis and management of malignant mesothelioma.Transl Lung Cancer Res, 9(S1):S3-S27.

Chou A, Toon CW and Clarkson A (2018). The epithelioid BAP1-negative and p16-positive phenotype predicts prolonged survival in pleural mesothelioma. Histopathology, 72(3):509-515.

Cigognetti M, Lonardi S and Fisogni S (2015). BAP1 (BRCA1-associated protein 1 ) is a highly specific marker for differentiating mesothelioma from reactive mesothelial proliferations. Mod Pathol, 28(8):1043-1057.

Cozzi I, Oprescu FA and Rullo E (2018). Loss of BRCA1-associated protein 1 (BAP1) expression is useful in diagnostic cytopathology of malignant mesothelioma in effusions. Diagn Cytopathol, 46 (1):9-14.

Dai L, Guinea MC and Slomiany MG (2013). CD147Dependent Heterogeneity in Malignant and Chemoresistant Properties of Cancer Cells. Am J Pathol, 182(2):577-585.

Erber R, Warth A and Muley T (2020). BAP1 Loss is a Useful Adjunct to Distinguish Malignant Mesothelioma Including the Adenomatoid-like Variant From Benign Adenomatoid Tumors. Appl Immunohistochem Mol Morphol, 28(1):6773.

Hatem L, Mclntire PJ and He B (2019). The role of BRCA1-associated protein 1 in the diagnosis of malignant mesothelioma in effusion and fineneedle aspiration cytology. Diagn Cytopathol, 47(3):160-165.

Hida T, Hamasaki M and Matsumoto S (2017). Immunohistochemical detection of MTAP and BAP1 protein loss for mesothelioma diagnosis: Comparison with 9p21 FISH and BAP1 immunohistochemistry. Lung Cancer, 104:98105.

Husain AN, Colby TV and Ordóñez NG (2018). Guidelines for Pathologic Diagnosis of Malignant Mesothelioma 2017 Update of the Consensus Statement From the International Mesothelioma Interest Group. Arch Pathol Lab Med, 142(1):89-108.

Hwang HC, Sheffield BS and Rodriguez S (2016)(a). Utility of BAP1 Immunohistochemistry and p16 (CDKN2A) FISH in the Diagnosis of Malignant Mesothelioma in Effusion Cytology Specimens. Am J Surg Pathol, 40(1):120-126.

Hwang HC, Pyott S and Rodriguez S (2016) $($ b). BAP1 Immunohistochemistry and p16 FISH in the Diagnosis of Sarcomatous and Desmoplastic Mesotheliomas. Am J Surg Pathol, 40(5):714718.

Kinoshita Y, Hamasaki M and Yoshimura M (2018)(a). A combination of MTAP and BAP1 immunohistochemistry is effective for distinguishing sarcomatoid mesothelioma from fibrous pleuritis. Lung Cancer, 125:198-204.

Kinoshita Y, Hida T and Hamasaki M (2018)(b). A combination of MTAP and BAP1 
immunohistochemistry in pleural effusion cytology for the diagnosis of mesothelioma. Cancer Cytopathol, 126(1):54-63.

McGregor SM, Dunning R and Hyjek E (2015). BAP1 facilitates diagnostic objectivity, classification, and prognostication in malignant pleural mesothelioma. Hum Pathol, 46(11):1670-1678.

Minato $\mathrm{H}$, Kurose $\mathrm{N}$ and Fukushima M (2014). Comparative Immunohistochemical Analysis of IMP3, GLUT1, EMA, CD146, and Desmin for Distinguishing Malignant Mesothelioma From Reactive Mesothelial Cells. Am J Clin Pathol, 141(1):85-93.

Monaco S, Mehrad M and Dacic S (2018). Recent Advances in the Diagnosis of Malignant Mesothelioma. Adv Anat Pathol, 25(1):24-30.

Nasu M, Emi M and Pastorino S (2015).High Incidence of Somatic BAP1 Alterations in Sporadic Malignant Mesothelioma. J Thorac Oncol, 10(4):565-576.

Paintal A, Raparia K and Zakowski MF (2013). The diagnosis of malignant mesothelioma in effusion cytology. Cancer Cytopathol, 121(12):703-707.

Pinheiro C, Longatto-Filho A and Soares TR (2012). CD147 immunohistochemistry discriminates between reactive mesothelial cells and malignant mesothelioma. Diagn Cytopathol, 40(6):478-483.
Ray M and Kindler HL (2009). Malignant Pleural Mesothelioma. Chest, 136(3):888-896.

Righi L, Duregon E and Vatrano S (2016). BRCA1Associated Protein 1 (BAP1) Immunohistochemical Expression as a Diagnostic Tool in Malignant Pleural Mesothelioma Classification: A Large Retrospective Study .J Thorac Oncol., 11(11):2006-2017.

Robinson BWS and Lake RA (2005). Advances in Malignant Mesothelioma. $N$ Engl J Med, 353(15):1591-1603.

Shinozaki-Ushiku A, Ushiku T and Morita S (2017). Diagnostic utility of BAP1 and EZH2 expression in malignant mesothelioma. Histopathology, 70(5):722-733.

Walts AE, Hiroshima $K$ and McGregor SM (2016). BAP1 Immunostainand CDKN2A(p16) FISH Analysis. Diagn Cytopathol, 44(7):599-606.

Yoshimura M, Kinoshita Y and Hamasaki M (2017). Diagnostic application of BAP1 immunohistochemistry to differentiate pleural mesothelioma from metastatic pleural tumours. Histopathology, 71(6):1011-1014.

Yoshimura M, Kinoshita Y and Hamasaki M (2019). Highly expressed EZH2 in combination with BAP1 and MTAP loss, as detected by immunohistochemistry, is useful for differentiating malignant pleural mesothelioma from reactive mesothelial hyperplasia. Lung Cancer, 130:187-193. 



\section{Egyptian Association for Cancer Research (EACR)}

http://eacr.tanta.edu.eg/

EACR is an NGO society that was declared by the Ministry of Social Solidarity (Egypt) No. 1938 in 19/11/2014 based on the initiative of Prof. Mohamed Labib Salem, the current Chairman of EACR. EACR aims primarily to assist researchers, in particular young researchers in the field of cancer research through workshops, seminars and conferences. Its first international annual conference entitled "Anti-Cancer Drug Discovery" was successfully organized in April 2019 (http://acdd.tanta.edu.eg). Additionally, EACR aims to raise the awareness of the society about the importance of scientific research in the field of cancer research in prediction, early diagnosis and treatment of cancer. EACR is also keen to outreach the scientific community with periodicals and news on cancer research including peer-reviewed scientific journals for the publication of cutting-edge research. The official scientific journal of EACR is "International Journal of Cancer and biomedical Research (IJCBR: https://jcbr.journals.ekb.eg) was successfully issued in 2017 and has been sponsored by the Egyptian Knowledge Bank (EKB: www.ekb.eg).

\section{EACR Chairman,}

Prof. Mohamed Labib Salem, PhD

Professor of Immunology

Faculty of Science, Tanta Universiy, Egypt 


\section{GUIDE FOR AUTHORS}

Publisher :The International Journal of Cancer and Biomedical Research (IJCBR) is an International and interdisciplinary journal of preclinical and clinical studies in the area of cancer and biomedical research. It is a peer-reviewed journal in English, published quarterly (in March, June, September, and December) by the Egyptian Association for Cancer Research (EACR) in both print and online formats (4 issues making a volume). Special issues or supplements may also be produced from time to time upon agreement with the Editorial Board.

Scope :The main aim of IJCBR is to attract the best research in animal and human biology in health and diseases from across the spectrum of the biomedical sciences at the molecular, cellular, organ, and whole animal levels especially those that are related to cancer research, including causes, prediction, diagnosis, prognosis, and therapy.

Publication Fees :The journal does charge for submission, processing, or publication of manuscripts (2000 LE for Egyptians or $250 \$$ for non-Egyptians; EACR members receive 15\% discount on publication). Of them Peer-review fees (300 LE) should be paid on submission (non-refundable). For the fast-track production of the accepted manuscript, another 500 LE is paid.

General specifications for different types of article

- Submitted manuscripts should not have been published previously, except in a limited form (e.g. short communication to a symposium or as part of MSc or PhD theses) and should not be under consideration for publication by other journals.

- All co-authors should agree with the content of the manuscript. Authors must have obtained permission to use any copyrighted material in the manuscript before submission.

IJCBR publishes different types of articles

- Original Article (6000 words with $\mathbf{4}$ tables and $\mathbf{4}$ figures, maximum $\mathbf{8}$ display items): Articles with novel findings are the target of IJCBR. Articles presenting a detailed description of a new technique, comparison of existing methods, meta-analyses with comprehensive and in-depth discussion are considered. Papers in a numbered series are not accepted unless all are submitted at the same time.

- Short communications or case study (3000 words with $\mathbf{4}$ display items): Short communications present exceptionally exciting, novel or timely contents are considered. They will be peer-reviewed in the same way as research papers. The references are restricted to 15 .

- Reviews or systematic review (9000 words with $\mathbf{1 0}$ display items): They are invited by the Editorial Board or unsolicited. Review articles have to be contemporary and comprehensive and add information to the knowledge. Sharp critical analyses of novel data or concepts are encouraged. When relevant, a statistical analysis of data and a meta-analysis approach are recommended.

- Opinion papers, letter to the editor or comment to the editor (1500 words with $\mathbf{2}$ display items): They are submitted by invitation of the Editorial Board. They are short papers, which aim to inform scientists, industry, and the public and policymakers about cutting-edge issues in research or the impact of research. They reflect the opinion of their authors who bear full responsibility of the published paper. The references are restricted to 10 .

- Conference/Symposium papers: The journal will consider for publication the results of original work and critical reviews that are presented at conferences/symposia. Symposium organizers who wish to publish bundles of papers from a symposium/conference in IJCBR should first contact the Editor-in-Chief of the IJCBR (EACR@unv.tanta.edu.eg) for agreement. Supplementary material can be proposed and will be made available online. The responsibility for the preparation of a paper in a form suitable for publication lies with the author.

- Thesis: IJCBR can publish the summary and abstract of Master and PhD theses in a special issue.

English: Good quality of written English is required. Spelling may be in British or American English but must be consistent throughout the paper. Care should be exercised in the use of biological terminology that is ill-defined or of local familiarity only. We recommend that authors have their manuscripts checked by an English language native speaker before submission.

Manuscript layout: Manuscripts should be prepared using a standard word processing program and presented in a clear readable format with easily identified sections and headings. The manuscript layout is based on the following directions.

- The main text contains Title, Abstract, Keywords, Introduction, Material and Methods, Results, Discussion, References, Tables, figures.

- The title needs to be concise and informative. Use bold, with an initial capital for the first word only and for words that ordinarily take capitals.

- Short (running) title (max 80 characters including spacing).

- The article text should be typed with double line spacing with wide margins $(2.5 \mathrm{~cm})$.

- The lines must be continuously numbered; the pages must also be numbered.

- Font Calibri 12 should be used for the text, and 12 for the tables, figure legends and references.

- The sections should typically be assembled in the following order:

- Title page contains title, authors' names, full affiliations, acknowledgements and the corresponding author's contacts and Short title.

Abstract (max 250 words, single paragraph): The abstract should be complete and understandable without citation, references, table, or figure. Use structured abstract: Background, Aim, Materials \& Methods, Results and Conclusion. The context and the rationale of the study are presented succinctly to support the objectives. The experimental methods and main results are summarized but should not be overburdened by numerical values or probability values. The abstract ends with a short and clear conclusion. 
Keywords: Up to five short and specific keywords should complement the title with respect to indicating the subject of the paper in alphabetic order.

Introduction: The introduction briefly outlines the context of the work, presents the current issues that the authors are addressing and the rationale to support the objectives, and clearly defines the objectives.

Material and methods: Material and methods should be described in sufficient details so that others can repeat the experiment. Reference to previously published work may be used to give methodological details, provided that said publications are readily accessible and in English. The code of ethics should be followed for all experiments use animals or human samples.

Statistical analysis of results: The statistical design and the models of statistical analysis must be described, as well as each of the statistical methods used. Sufficient statistical details must be given to allow replication of the statistical analysis. The experimental unit should be defined (e.g., individual or group of animals).

Results: Data are presented as tables and figures. Brief description of the results for each table and figure should be presented. Unpublished data can be mentioned when necessary.

Discussion: Should be separate from the Results section and should focus only on intra- and inter-data discussion (the data in the results section) as well as with the relative data in the literature. Don't repeat information already presented in the Introduction section. Start the first paragraph in the Discussion with a paragraph stating the rationale behind the study, the objectives, and the main findings. End Discussion with a short conclusion.

Acknowledgements: In this section, the authors may acknowledge (briefly) their support staff.

Conflict of interest: All papers with a potential conflict of interest must include a description/explanation in a separate heading.

Funding details: The authors should state the source of findings of the study (with research funder and/or grant number). If no fund, the authors should state that the study is self-funded.

\section{References}

Citation of references: In the text, references should be cited by the author(s) surname(s) and the year of publication (e.g. Salem, 2020). References with two authors should be cited with both surnames (e.g. Salem and Meshrif, 2021). References with three or more authors should be cited with the first author followed by et al. (in italics; e.g. Salem et al., 2021). Names of organizations used as authors (e.g. Food and Drug Administration) should be written out in full in the list of references and on the first mention in the text. Subsequent mentions may be abbreviated (e.g. FDA).

- List of references. Literature cited should be listed in alphabetical order by authors' names. It is the author's responsibility to ensure that all references are correct. All authors should be written and so the full journal name.

- $\quad$ References from journal articles are formatted in APA as this example: Al-Amoudi WM (2018). Toxic effects of Lambdacyhalothrin on the rat thyroid. Involvement of oxidative stress and ameliorative effect of ginger extract. Toxicology Reports, 5: 728-736.

- $\quad$ References from books or official reports are formatted as this example. Kebreab E, Dijkstra ANM, Bannink A, Gerrits WJJ, \& France J (2006). Nutrient digestion and utilization in farm animals. CABI Publishing. Wallingford, UK.

- References from chapters or parts of books are formatted as this example. Nozière $P, \&$ Hoch $T$ (2006). Modelling fluxes of volatile fatty acids from rumen to portal blood. In: Nutrient digestion and utilization in farm animals (Kebreab E, Dijkstra ANM, Bannink A, Gerrits WJJ \& France J, eds.), pp. 40-47. CABI Publishing. Wallingford, UK.

Tables: The data should be presented in tables or in graphs, not both.

- Each table should be placed on a separate page at the end of the main text.

- Tables are numbered consecutively using Arabic numbering. They are referred to as Table 1 , Table 2, etc., with capital ' $T$ ', no italics

- $\quad$ Each table has its explanatory caption. The caption is sufficient to permit the table to be understood without reference to the text.

- Abbreviations used in tables/figures have to be defined either as footnotes or in the caption.

\section{Figures}

- $\quad$ Package the figures in a single PowerPoint file. Each figure in a separate slide.

- Figure size should be readable in a width of approximately 8-175 $\mathrm{mm}$ (i.e. the maximum size of printing over two columns).

- Ensure that the font size is large enough to be readable at the final print size, use Calibri font to ensure that they are consistent throughout the figures.

- $\quad$ The figures should preferably be provided as TIFF or EPS files.

- The resolutions of figures must be at least $300 \mathrm{dpi}$.

- Preparation of images for a manuscript: For guidance, we refer to the Journal of Cell Biology's instructions to authors (http://jcb.rupress.org/site/misc/ifora.xhtml\#image_aquisition).

- If a cropped image is included in the main text of a paper (e.g. a few lanes of a gel), display the full original image, including the appropriate controls, the molecular size ladder and/or the scale as relevant, as a single figure in a Supplementary Material file to facilitate peer-review and for subsequent online publication.

- Supplementary material is submitted along with the main manuscript in a separate file and identified at uploading as "Supplementary File - for Online Publication Only" The title of the article is included at the top of the supplementary material.

Corresponding author's guidelines: Upon acceptance the corresponding author is required to send his/her recent formal photo to be attached to the front page of the article. 


\title{
International Journal of Cancer \& Biomedical Research
}

(IJCBR) Online ISSN 2682-2628

\author{
Editor-in-Chief \\ Mohamed Labib Salem, PhD \\ Tanta University, Egypt
}

\begin{tabular}{l} 
EACR Board \\
\hline Nehal Elmashad, MD \\
Tanta University, Egypt \\
Nabil Mohy Eldin, PhD \\
Kafrelsheikh University, Egypt \\
Doaa Al-Ghareeb, PhD \\
Alexandria University, Egypt \\
Abdel-Aziz Zidan, PhD \\
Damanhour University, Egypt
\end{tabular}

\begin{tabular}{l} 
Managing Editor \\
\hline Wesam Meshrif, PhD \\
Tanta University, Egypt \\
Sohaila Galal, PhD \\
Tanta University, Egypt \\
Production and Contact \\
\hline Hamdi Kandil \\
Tanta University, Egypt \\
Email: ljcbr100@gmail.com
\end{tabular}

\section{Advisory Board}

Alberto Montero, MD

Taussig Cancer Center, Cleveland,

USA

Yi Zhang, MD

Zhengzhou University, China

Mark Robunstein, Ph D

Medical University of South

Carolina, USA

Mohsen Farid, Ph D

Derby University, USA

Natarajan Muthusamy, Ph D

Ohio State University, USA

Hideki Kasuya, MD

Nagoya University, Japan

Sherif El-Khamisy, Ph D

Sheffield University, UK

Mohamed Ghanem, Ph D

Kafr Elshikh University, Egypt

Sayed Bakry, Ph D

Alazhar University, Egypt

Sameh Ali, Ph D

Nationa Liver Institute, Egypt

Gamal Badr, Ph D

Assuit University, Egypt

Nadia Hamdy, Pharm D

Ain Shams University, Egypt

\section{Editorial Board}

\section{Clinical studies}

Hesham Tawfik, MD

Tanta University, Egypt

Mohamed Attia, MD

Tanta University, Egypt

Mohamed Elshanshory, MD

Tanta University, Egypt

Essam Elshiekh, MD

Tanta Cancer Center, Egypt

Rasha Eraky, MD

Tanta University, Egypt

Shaima Abou-Kjatwa, MD

Tanta University, Egypt

Marcela Diaz, MD

Cleveland Clinic Foundation, USA

Mohamed Abou-El-Enein, MD

Charité Universitätsmedizin Berlin,

Germany
Alaa Eldin Almostafa, MD

McGill University, Canada

Olfat Gadallah, MD

Tanta University, Egypt

Nagla Sarhan, MD

Tanta University, Egypt

Naglaa Fathy, Pharm D

Zagazik University, Egypt

Mohamed Salama, MD

Mansoura University, Egypt

Mona Marie, MD

Alexandria University, Egypt

Preclinical studies

Mostafa El-Sheekh

Tanta University, Egypt

El-Refai Kenawy, Ph D

Tanta University, Egypt

Mohamed Noureldin, Ph D

Banaha University, Egypt

Yousry Albolkiny, Ph D

Tanta University, Egypt

Elsayed Salim, Ph D

Tanta University, Egypt

Shengdian Wang, Ph D

Chinese Academy of Sciences,

China

Sabry El Naggar, Ph D

Tnata Univesity, Egypr

Faris Alenzi, Ph D

Prince Sattam bin Abdulaziz

University, KSA

Ibrahim El-Sayed, Ph D

Menoufia University, Egypt

Tarek Aboul-Fadl, Ph D

Assiut University, Egypt

Rabab Khairat, Ph D

National Research Center,

Giza, Egypt

Wael Lotfy, Ph D

Alexandria University, Egypt

Ashraf Tabll, Ph D

National Research Center, Egypt

Nahla Shoukry, Ph D

Suez University, Egypt
Medhat Eldenary, Ph D

Tanta University, Egypt

Azza Hasan, Ph D

Menufia University, Egypt

Nanees Gamal Eldin, Ph D

Tanta University, Egypt

Mohamed Mansour, UK

Sabbah Hammoury, Ph D

Alexandria Ayadi Almostaqba

Oncology Hospital, Egypt

Nehal Aboulfotoh, Ph D

Zewail City for Science and

Technology, Cairo, Egypt

Amir Elkhami, Ph D

Galaxo, San Francisco, USA

Ahmed Alzohairy, Ph D

Zagazi University, Egypt

Wgady Khalil, Ph D

National Research Center, Egypt

Amr Amin, Ph D

United Arab Emirates

University, UAE

AbdelRahman Zekri, Ph D

National Cancer Institute, Egypt

Hussein Khamis, Ph D

Alexandria University, Egypt

Magdy Mahfouz, Ph D

Kafr Elsheikh University, Egypt

Ehab Elbedewey, Ph D

Tanta University, Egypt

Abeer Badr, Ph D

Cairo University, Egypt

Mamdooh Ghoneum, Ph D

Charles Drew University of

Medicine \& Science, USA

Haiam Abou Elela, Ph D

National Institute of Oceanography and Fisherie, Egypt

Maha EL-Demellawi, Ph D City for Scientific Research \&

Technology Applications, Egypt

Desouky Abd-El-Haleem, Ph D

City for Scientific Research \&

Technology Applications, Egypt 